\title{
Development and Application of Blast Casting Technique in Large-Scale Surface Mines: A Case Study of Heidaigou Surface Coal Mine in China
}

\author{
Li Ma, ${ }^{1,2,3}$ Kemin Li, ${ }^{2}$ Xiaohua Ding, ${ }^{2,3}$ Hongge Peng, ${ }^{2,3}$ and Shuangshuang Xiao ${ }^{2,3}$ \\ ${ }^{1}$ State Key Laboratory for Geomechanics \& Deep Underground Engineering, China University of Mining and Technology, \\ Xuzhou, Jiangsu 221116, China \\ ${ }^{2}$ School of Mines, State Key Laboratory of Coal Resources and Safe Mining, China University of Mining and Technology, \\ Xuzhou, Jiangsu 221116, China \\ ${ }^{3}$ Key Laboratory of Deep Coal Resource Mining (CUMT), Ministry of Education, Xuzhou, Jiangsu 221116, China
}

Correspondence should be addressed to Kemin Li; likemin513@126.com

Received 14 June 2015; Accepted 20 December 2015

Academic Editor: Mickaël Lallart

Copyright (C) $2016 \mathrm{Li} \mathrm{Ma}$ et al. This is an open access article distributed under the Creative Commons Attribution License, which permits unrestricted use, distribution, and reproduction in any medium, provided the original work is properly cited.

Blast casting is a high-efficiency technique applied in surface mines for overburden removal and results in stripping cost savings. According to ballistic theory and center-of-mass frame basic movement principles, key factors influencing blast casting effect were analyzed, which include bench height and mining panel width, inclined angle of blast holes, explosive unit consumption (EUC), delay-time interval, presplitting, and blast hole pattern parameters. An intelligent design software was developed for obtaining better breaking and casting effect, and the error rates predicted with actual result can be controlled with 10\%. Blast casting technique was successfully applied in Heidaigou Surface Coal Mine (HSCM) with more than 34\% of material casted into the inner dump. A ramp ditch was set within the middle inner dump for coal transportation. The procedure of stripping and excavating was implemented separately and alternately in the two sections around the middle ramp ditch. An unconstrained-nonlinear model was deduced for optimizing the shift distance of the middle ramp. The calculation results show that optimum shift distance of HSCM is $480 \mathrm{~m}$, and the middle ditch should be shifted after 6 blast casting mining panels being stripped.

\section{Introduction}

Blast casting is a high-efficient technique applied in surface mines for overburden removal, in which overburden is cast directly into the decoaled area with the minimal left to be rehandled by other types of mechanical equipment [1]. All over the world, this method has successfully been applied to horizontal and dipping coal seams to offset the mining cost of conventional drilling and blasting methods where the increasing stripping ratios have become uneconomical [24]. This technique was applied in surface coal mines and other noncoal open-pit mines, as is reported in strip-mining phosphate rock of Jordan [5].

In surface mining operation, rock fragmentation and overburden removal are two important tasks that are required. The in situ rock mass is broken into fragmented blocks by a loosen coefficient (LC), and the blasted overburden is removed by draglines, shovels, or loaders. As blast casting plays an important role in overburden breaking and removal, it has emerged as a lower cost alternative to conventional methods in overburden removing [6]. Blast casting aims at increasing the volumes casted into spoil piles and reducing the overburden percentage to be rehandled by stripping equipment [7].

Blast casting has a series of advantages, such as higher productivity, reducing the operation costs and equipment's capital costs. Overburden casting is not suitable for all mines and not all mines that adopt it will get the same results. The percentage casted into mined-out pits, called effective casting ratio (ECR), depends on the factors of engineering geology of the deposit and strata, blast parameters, the nature, and characteristics of explosives to be used. Therefore, optimal 
TABLE 1: Coal occurrence conditions of major opencast fields in China.

\begin{tabular}{|c|c|c|c|c|c|c|c|}
\hline \multirow[b]{2}{*}{ Coal fields } & \multicolumn{4}{|c|}{ Coal seam } & \multirow[b]{2}{*}{$\begin{array}{l}\text { Overburden } \\
\text { thickness/m }\end{array}$} & \multirow[b]{2}{*}{$\begin{array}{l}\text { Rock property } \\
\text { of overburden }\end{array}$} & \multirow[b]{2}{*}{ Overall stripping ratio $/ \mathrm{m}^{3} \cdot \mathrm{t}^{-1}$} \\
\hline & $\begin{array}{l}\text { Average coal } \\
\text { thickness/m }\end{array}$ & $\begin{array}{c}\text { Number of } \\
\text { main minable } \\
\text { seams }\end{array}$ & $\begin{array}{c}\text { Seam } \\
\text { inclination } /\left(^{\circ}\right)\end{array}$ & Structure & & & \\
\hline Pingshuo & 30 & 3 & $<10$ & Simpler & $100 \sim 200$ & $f=4 \sim 6$ & 5.59 \\
\hline Zhungeer & 33.65 & 3 & $5 \sim 10$ & Simple & $0 \sim 110$ & $f=3.4 \sim 6$ & 5.59 \\
\hline Shenfu & 17.73 & 3 & $1 \sim 2$ & Simple & $23 \sim 60$ & Medium hard & 6.16 \\
\hline Dongsheng & $10.4 \sim 27$ & 2 & $1 \sim 2$ & Simple & $<70$ & Medium hard & $2 \sim 5$ \\
\hline Shengli & 34.23 & 5 & $3 \sim 4$ & Simpler & $0 \sim 200$ & Medium hard & $2.5 \sim 2.6$ \\
\hline Hebaopian & 34.7 & $1 \sim 6$ & $5 \sim 10$ & Simple & $100 \sim 170$ & Medium hard & $4 \sim 6$ \\
\hline Yinmin & 42 & $2 \sim 3$ & $3 \sim 6$ & Simple & $5 \sim 20$ & $f=1 \sim 2$ & 3.13 \\
\hline Huolinhe & $10 \sim 30$ & 4 & $5 \sim 15$ & Complex & & $f=4 \sim 5$ & $4 \sim 5$ \\
\hline Yuanbaoshan & 76.7 & 2 & $3 \sim 8$ & Simpler & & $\begin{array}{l}\text { Soft-medium } \\
\text { hard }\end{array}$ & 3.96 \\
\hline Baorixile & 44.82 & 5 & $5 \sim 10$ & Simpler & $20 \sim 100$ & Medium hard & 3.87 \\
\hline Zhaotong & $18 \sim 55$ & 3 & $3 \sim 10$ & Simple & & Soft & 1.6 \\
\hline Xiaolongtan & 70 & & $8 \sim 20$ & Simple & & Soft & 0.84 \\
\hline Wulumuqi & & 2 & 45 & Complex & & & \\
\hline
\end{tabular}

blast design parameters for definite strata condition can result in higher percentage of overburden casted into mined-out pits. According to the trajectory theory, objects can fly farther. Therefore, in order to get larger ECR, inclined hole with the angles of 65 to 90 degrees was always used in blast casting. The lesser the angle of hole inclination is, the difficult the operation and working will become.

Blast casting technique was applied in various surface mines around the world, and the percentage of $30 \%$ or even more ECR can be achieved. It has a larger advantage of reducing mining costs. It can generate huge economic benefits when adopted in suitable rock strata and geological conditions, in which the matched equipment or mining technology is the major factors influencing mining sequence. Usually, dragline stripping system was adopted in most mines to handle the rest of overburden not casted into mined-out pits; the discontinuous system of shovel-truck was applied as well.

As the coal seam characteristics of simple structure and proper thickness and with a dip ranging from horizontal to gentle are necessary for adopting blast casting and dragline stripping system, the major coal fields of China thus have the basic conditions for applying this technique as shown in Table 1 [8]. Therefore, the blast casting technique adopting equipment such as dragline or shovels and trucks have a wide application in future mining worldwide and which in turn will generate huge benefits.

\section{Theory and Design of Blast Casting}

2.1. Key Factors Influencing Blast Casting Effect. Rock will be broken into different sizes and shapes when blasting is influenced by number and direction of joints and fractures in the rock. The determination of the initial casting velocity and collisions between casting rocks are inevitable effect factors during the casting process. The blast casting model is shown in Figure 1; casting rocks fly in a ballistic trajectory according to the center-of-mass frame basic movement principles without regard to air friction condition [9]:

$$
v=\sqrt{\frac{g S}{\sin ^{2} \alpha\left(1+\tan \alpha \cdot H^{\prime} / S\right)}},
$$

where $v$ is initial velocity of casting rocks, $\mathrm{m} / \mathrm{s} ; S$ is horizontal distance of casting rocks start and end position, $\mathrm{m} ; \alpha$ is casting angle of casting rocks, ${ }^{\circ} ; H^{\prime}$ is vertical distance of casting rocks start and end position, $m$.

According to the energy conservation law, primary energy of casting rocks was provided by the explosive's explosion:

$$
\frac{1}{2} \rho v^{2}=q e \eta
$$

where $\rho$ is rock density; $q$ is EUC; $e$ is explosive specific energy; $\eta$ is effective blasting effect coefficient of plane charge with extreme dimension. It is the ratio of kinetic energy of rock casting to total blast energy of plane charge and depends on plane charge size, rock characteristics, EUC, and explosive types to a large extent.

Based on the principle of blast casting effect and definition of ECR, ECR can be regarded as specific value of a number of microrocks stacking in mined-out area, and casting distance is the direct factor representing ECR:

$$
S=\sqrt{\frac{4 \eta e q\left(H^{\prime}+S \cot \alpha\right) \sin ^{2} \alpha}{\rho g} .}
$$

The key factors influencing blast casting effect can be classified as follows in line with the principle of blast casting effect $[10,11]$. 


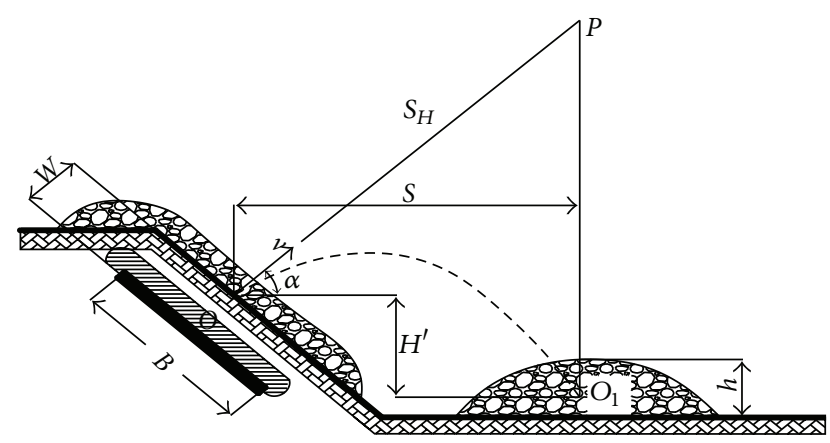

FIgURe 1: The blast casting model.

2.1.1. Bench Height, $H$, and Mining Panel Width, $W$. The amount of blast casting practice and research show that the three row blast holes close to the free face act as the main role on casting, and it is necessary to determine the optimal resistance line in ensuring maximum casting velocity. What is more, ECR will decrease with increasing mining panel width. The smaller the mining panel width, $W$, is, the greater the active meaning it has on ECR.

Both bench height (the depth of blast holes) and mining panel width are key factors influencing ECR, as shown in Figure 2. The charge height changes consistent with bench height, with the fixed length of extra-deep and stem length of blast holes. In addition, rock fragmentation effect is related to explosion pressure, while explosion pressure has relation to explosive density, detonation velocity, charging height, and detonation gas effect time [12]:

$$
P=\frac{1}{8} \rho D^{8 / 3}\left(\frac{t}{L}\right)^{2 / 3} \exp \left(1-\frac{D t}{L}\right)^{2 / 3}
$$

where $P$ is the explosion pressure, $\mathrm{Pa} ; \rho$ is the explosive density, $\mathrm{kg} / \mathrm{m}^{3} ; D$ is the explosive detonation velocity, $\mathrm{m} / \mathrm{s}$; $L$ is the charge length, $\mathrm{m}$; and $t$ is the detonation gas effect time, s.

According to formula (4), explosion pressure decreases exponentially with increasing detonation gas effect time. At a fixed effect time, the explosion pressure will increase with increasing bench height, while the reduction range of explosion pressure decreases. Therefore, increasing the bench height has a significant effect to enhance explosion pressure.

Moreover, there is a linear relationship among casting amount with bench height $H$ and mining panel width $W$ [13], as shown in Figure 3.

With the increasing in $H / W$, effective amount casted into mined-out area will increase. While ECR has a positive correlation with bench height and the fixed mining panel width, the value of $H / W$ is always around $0.4 \sim 0.85$ for achieving better casting effect.

2.1.2. Inclined Angle of Blast Holes. According to ballistics theory, the relationship of rock casting distance with inclined angle of blast holes is deduced as

$$
S=v \cos \alpha\left[\frac{v \sin \alpha}{g}+\sqrt{\frac{2}{g}\left(\frac{v^{2} \sin ^{2} \alpha}{2 g}+H^{\prime}\right)}\right]
$$

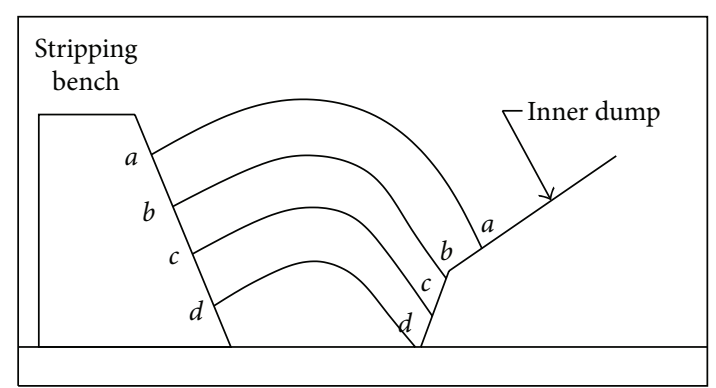

FiguRE 2: Effects of bench height on casting overburden.

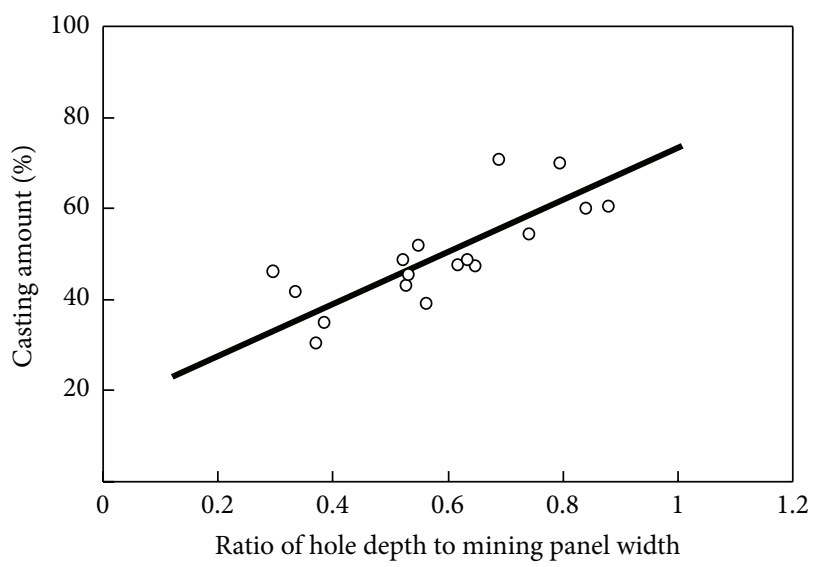

FIGURE 3: Relationship between casting volume and bench height with mining panel width.

The casting distance increases with increasing inclined angles and then decreases when inclined angle achieves a certain degree. That is to say, casting distance has a quadratic parabola relationship with inclined angle of blast holes. What is more, inclined angle has a series of advantages compared with vertical holes $[14,15]$ :

(a) Inclined holes can make the resistance line uniform and increase effective utilization ratio of explosive energy to enhance fracture effect.

(b) Make the bench slope more stable and enhance working safety.

(c) Relative bench height can be increased by adopting inclined holes to improve casting effect.

(d) More explosives can be charged in one hole as the blast hole length is increased by the inclined angle, while with the row distance and hole distance it is increased.

2.1.3. EUC. To ensure blast casting effect, high energy explosive was always adopted in blast casting technique. It can be charged with high energy explosive only or composite explosives of high energy in general. With the two major functions of fracturing and casting, EUC in blast casting is always more than $0.6 \mathrm{~kg} / \mathrm{m}^{3}$, usually 2 or 3 times to loosening blast. 


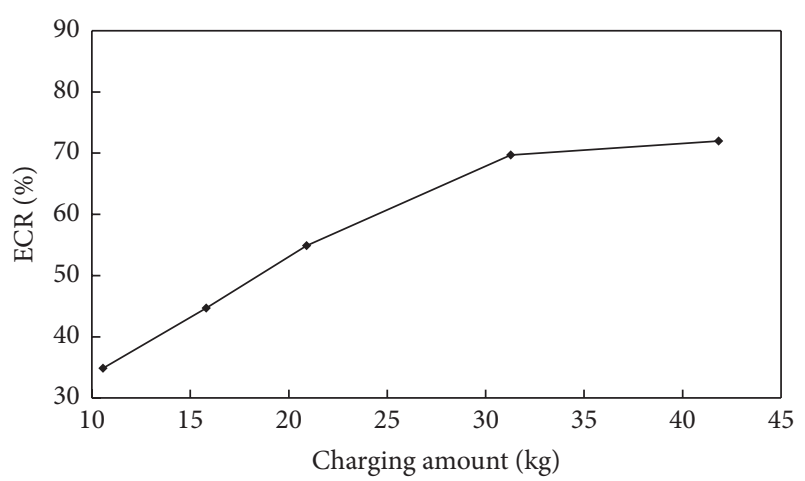

FIGURE 4: Relationship of casting ratio with charging amount.

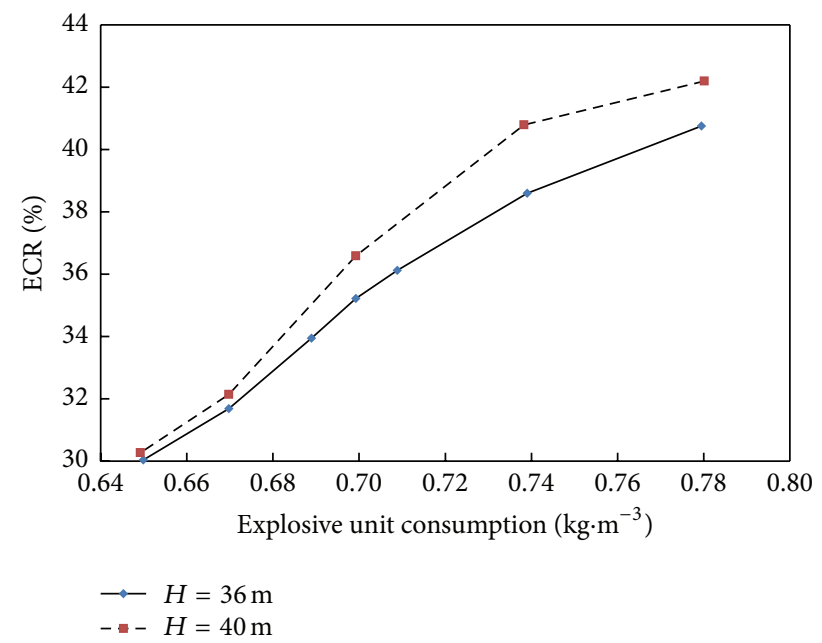

FIgURE 5: Relationship of casting ratio with EUC.

Figures 4 and 5 present the relationship of ECR with explosive charging amount (ECA) and EUC, respectively [1618]. It is obvious that ECR will increase with ECA and EUC increasing, but the increasing range decreases when ECA and EUC reached a certain value.

2.1.4. Delay-Time Interval. Shock wave reduces to stress wave after producing smashing destruction. Circumferential tensile stress and reflected radial tensile stress were derived under the effect of stress wave, consequently forming radial and circumferential cracks as shown in Figure 6. When two adjacent blast holes are detonated simultaneously, reflected radial tensile stress will increase on account of the stress wave superposition effect and result in greater range of broken cracks. Therefore, blast holes in one row should be detonated at the same time as much as possible to increase hole spacing, burden, or both.

Moreover, rock fragment size decreases as two adjacent holes in a row are detonated simultaneously, and the rock block will obtain higher initial velocity, thereby reducing EUC. Whereas the amount of rock and charge weight in one blast casting are large, millisecond blasting is of great significance to reducing the blast vibration effect and controlling blast hazards. But if the delay-time interval between two rows is excessively large, the blast holes and charges of the back rows will be destroyed by the blasting stresses of the front rows and affects blasting effect. On the contrary, if the delaytime interval between two rows is too small, it will generate severe damage on back rows.

The time interval between rows can be calculated according to the empirical formula [19]:

$$
t_{p}=(6 \sim 10) b
$$

where $t_{p}$ is the time interval between rows, ms, and $b$ is row spacing, $\mathrm{m}$.

According to experience home and abroad, the time interval between rows $t_{p}=75$ to $200 \mathrm{~ms}$ and the time interval between holes $t_{k}=10$ to $25 \mathrm{~ms}$.

2.1.5. Presplitting. During the process of blast casting in surface coal mining, presplitting is always detonated earlier than the major casting holes. The major effects of presplitting include defining the blast casting boundary, decreasing the blasting vibration, enhancing water drainage, and maintaining the stability on a fixed slope.

When the explosion's tensile stress $\sigma_{M}$ is greater than rock tensile strength, precracking will be formed at a certain width and acts as a better damping effect. The coefficient of stress wave transmission is given as

$$
R_{t}=\frac{A_{t}}{A_{i}}
$$

where $R_{t}$ is the stress wave transmission coefficient; $A_{i}$ is the incident wave amplitude value; $A_{t}$ is the transmission wave amplitude value.

Wave speed expression is given as

$$
v=A e^{-\alpha} \sin \omega t
$$

Therefore, decreasing amplitude ratio $\varepsilon$ can be expressed as

$$
\varepsilon=\frac{\left|v_{i}\right|_{\max }-\left|v_{t}\right|_{\max }}{\left|v_{i}\right|_{\max }}=\frac{\left|A_{i}\right|_{\max }-\left|A_{t}\right|_{\max }}{\left|A_{i}\right|_{\max }}=1-R_{t} .
$$

2.1.6. Blast Hole Pattern Parameters. By adopting column charge as plane charge method, explosive energy of the adjacent holes induces compression on the surrounding rock mass, and rock mass is broken by air wedge effect with the plane charge formed. On the casting direction, explosive energy is used to overcome rock resistance line (row distance). When the row distance is much small, detonation gas effect time decreases and results in detonation gas leaking early with the breaking effect being worsened. While the row distance is oversized, much energy will be consumed on overcoming rock resistance, and the energy for rock block casting will be less with casting effect worse.

2.2. Intelligent Design Method for Blast Casting. Geological conditions are the first and important factors influencing blast effect, and the factors cannot be considered thoroughly 


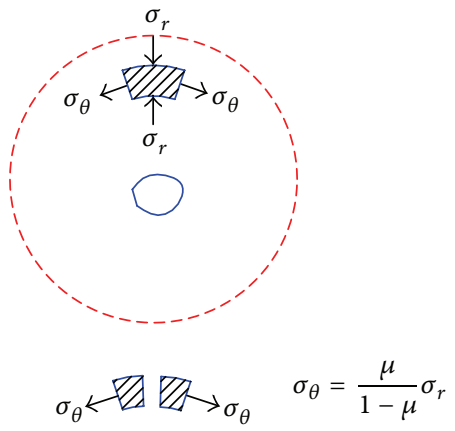

(a)

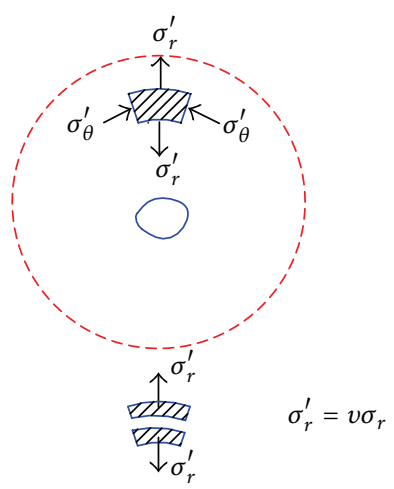

(b)

FIGURE 6: Formation mechanism of radial and circumferential cracks. $\sigma_{r}$, pressure stress; $\sigma_{\theta}$, circumferential tensile stress; $\sigma_{r}^{\prime}$, reflected radial tensile stress; $\sigma_{\theta}^{\prime}$, circumferential pressure stress.

in traditional manual design. For reducing labor intensity and increasing blast design veracity, intelligent design system had been developed with key features of blast design on the basis of geological information and blast casting effect prediction based on statistical analysis method [20, 21]. All functions of blasting design parameters, blast hole automatic arrangement, wire connection and time-delay, blast casting effect prediction, and design result exporting are combined in the intelligent design system. The intelligent blast casting design flowchart is shown in Figure 7.

2.2.1. Data Importing. Both geological drilling data and terrain data were imported to the system to build the mine geological model from which the geological situation of blasting area can be obtained. In addition, bench top surface and bench slope have key influence on blast design, with the bench top surface affecting the holes orifice elevation and bench slope affecting the front row resistance and blast effect. Bench top surface data and bench slope data can be obtained by GPS and 3D scanner, of which importing into the intelligent blast casting design system, the vector graph is generated as shown in Figure 8.

2.2.2. Blast Casting Design. According to predefined row burden, hole spacing, inclination angle, blast hole diameter, and hole pattern, blast holes are set in the blast area with relevant charging structure and explosive payload being correspondingly selected and assigned to blast holes. The next step is to optimize the front hole location in line with resistance relation of bench slope and then finish the wire connection design on the basis of delay-time interval and wire connection mode as shown in Figure 9.

2.2.3. Blast Casting Effect Prediction. The intelligent blast design results can meet the requirements of mines with different geological conditions; especially the main blasting effect factors of muck pile morphology, ECR and LC, can be predicted accurately as shown in Figure 10. The intelligent blast design system has been applied successfully in HSCM

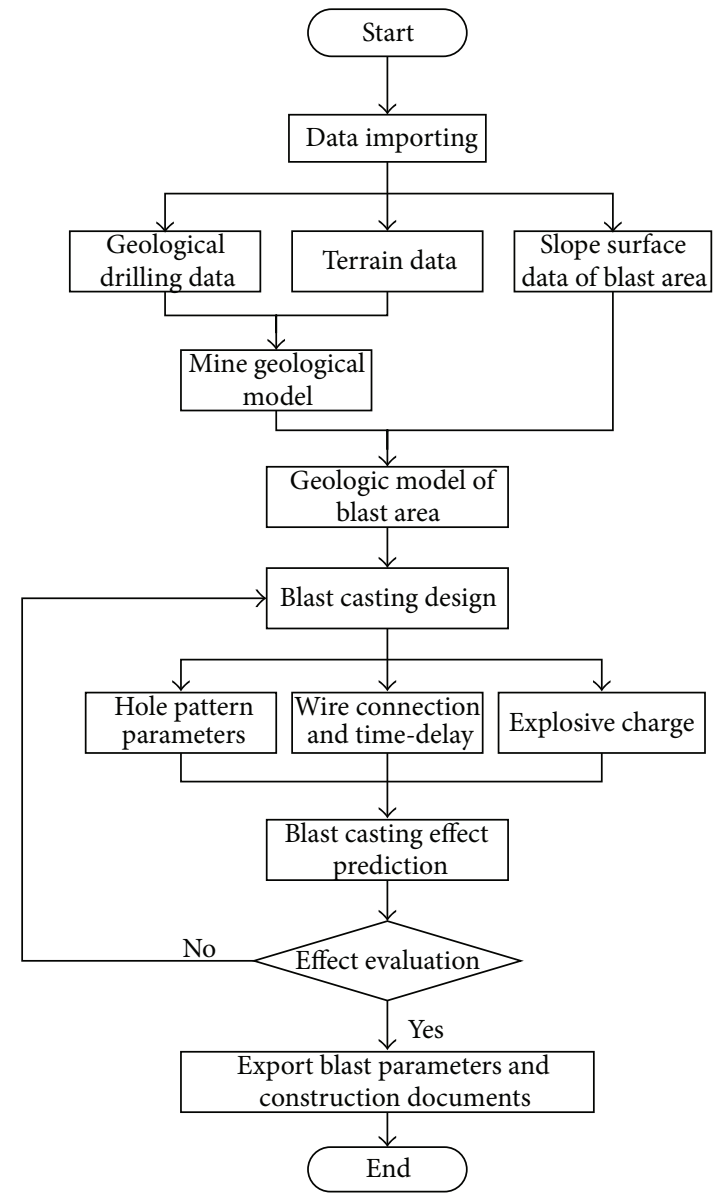

FIGURE 7: Flowchart of intelligent blast casting design.

for designing blast casting parameters. The statistical predicted error rate of blast casting muck pile effect is shown in Table 2.

It can be seen from Table 2 that the predicted average blasting effect can be in line with the actual values and the 
TABLE 2: Statistical predicted error rate of blast casting muck pile effect.

\begin{tabular}{|c|c|c|c|c|c|c|c|}
\hline & \multicolumn{2}{|c|}{ Prediction value } & \multicolumn{2}{|c|}{ Actual value } & \multicolumn{3}{|c|}{ Error rate (\%) } \\
\hline & LC & ECR & LC & ECR & LC & ECR & Curve \\
\hline Average & 1.2 & 0.28 & 1.18 & 0.31 & 1.69 & 9.13 & 4.15 \\
\hline $09 E 8-1$ & 1.3 & 0.31 & 1.26 & 0.23 & 3.17 & 33.77 & 4.97 \\
\hline $09 E 8-2$ & 1.23 & 0.27 & 1.19 & 0.26 & 3.36 & 1.98 & 3.49 \\
\hline $09 E 8-3$ & 1.21 & 0.26 & 1.13 & 0.26 & 7.08 & 1.13 & 2.99 \\
\hline $09 E 8-4$ & 1.17 & 0.25 & 1.13 & 0.28 & 3.54 & 9.50 & 5.68 \\
\hline $09 E 8-5$ & 1.19 & 0.28 & 1.2 & 0.34 & 0.83 & 17.13 & 3.43 \\
\hline $09 E 8-6$ & 1.21 & 0.29 & 1.17 & 0.35 & 3.42 & 16.40 & 4.69 \\
\hline $09 E 8-7$ & 1.2 & 0.31 & 1.17 & 0.37 & 2.56 & 16.51 & 4.25 \\
\hline $09 E 8-8$ & 1.21 & 0.3 & 1.24 & 0.36 & 2.42 & 16.00 & 3.59 \\
\hline $09 E 8-9$ & 1.22 & 0.3 & 1.15 & 0.32 & 6.09 & 7.52 & 4.28 \\
\hline
\end{tabular}

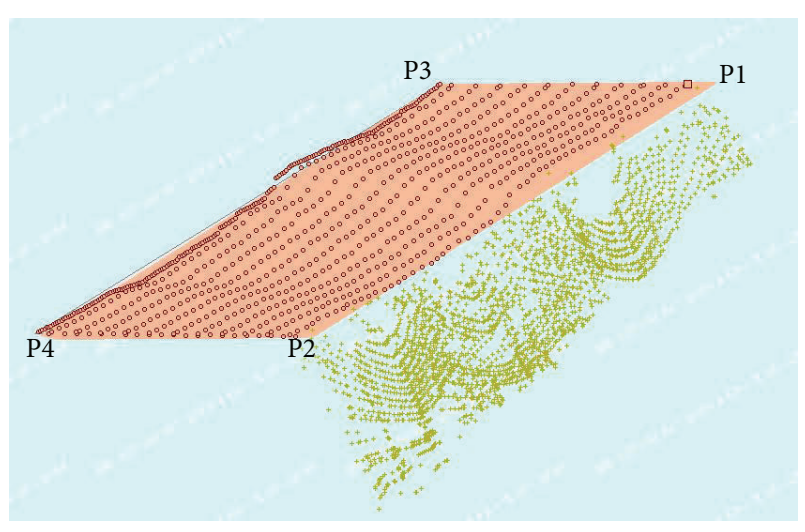

FIGURE 8: Generated vector graph by importing bench data.

error rates of the LC, ECR, and the muck-pile morphology are less than $10 \%$ indicating the accuracy of the predicted result.

\section{Blast Casting Applied in HSCM}

3.1. General Situation. HSCM with a current production capacity of $33 \mathrm{Mt} / \mathrm{annum}$ and production area of about $42.36 \mathrm{~km}^{2}$ is the largest production surface coal mine in China. It is located on the Zhungeer coal fields of Inner Mongolia autonomous region, as shown in Figure 11. Since opening up, the design and operations rely on the domestic reform. The main mineable coal seam is 6th coal with a dip ranging from horizontal to 5 degree. The average thickness is about $28.8 \mathrm{~m}$, overlying rock of 50 to $70 \mathrm{~m}$ and topsoil of $50 \mathrm{~m}$. The continuous system of bucket wheel excavator-belt conveyor was applied in topsoil mining. The overlying rock composed of clay rock and mudstone which was stripped off by shovel-truck discontinuous system [22, 23]. With the requirement for production capacity increasing and production costs reducing, blast casting technique with dragline stripping technology was introduced into HSCM since 2007, for removing rock with bench height no more than $40 \mathrm{~m}$ of the upper coal roof. After the technological transformation, the production capacity can achieve $20 \mathrm{Mt} / \mathrm{a}$, and the mining technology is composed of BWE-belt conveyor continuous system for topsoil, shovel-truck discontinuous system for upper rock, blast casting-dragline stripping system for rock overlying coal roof, and shovel-truck-crusher-belt conveyor semicontinuous system for coal, as shown in Figure 12.

3.2. Application of Blast Casting Technique. By considering the working processes, the effects of blast casting and dragline, the working face length, mining panel width, stripping bench height, and slope angle were designed as $2200 \mathrm{~m}$, $80 \mathrm{~m}, 40 \mathrm{~m}$, and 75 degree, respectively. The best blasting effect was also determined after several field experimentations. The spacing is around $9 \mathrm{~m}$ to $13 \mathrm{~m}$ and row burden ranges between $7 \mathrm{~m}$ and $9 \mathrm{~m}$. During blast casting operation with multiple holes and enormous amount of explosives used, the following was always selected to reduce effects on the highwall and the buildings. These are hole-by-hole initiation technique and the timing in milliseconds delay between rowto-row and hole-to-hole and within the holes. Time-delay interval between two holes in a row is always around $9 \mathrm{~ms}$ to $17 \mathrm{~ms}$ and $100 \mathrm{~ms}$ of first row to second row, $150 \mathrm{~ms}$ of second row to third row, $200 \mathrm{~ms}$ of third row to eighth row, $150 \mathrm{~ms}$ of eighth row to ninth row, and $100 \mathrm{~ms}$ of ninth row to tenth row. Successive charging is used in other rows with stemming height of $6.5 \mathrm{~m}$ to $7 \mathrm{~m}$, while interval charging is used in the last row to decrease the blasting vibration and reduces effects on slope stability of the next width. The blast casting technique used in HSCM is shown in Figure 13, and more than $34 \%$ of material was casted into the inner dump with this technique.

In areas with horizontal seam under steep slopes, the higher the highwall left standing, the greater the production of coal from that section of the permitted area. Explosive energy not only can fracture the rock during blast casting but also can damage rock bordering and the new highwall will be formed. Meanwhile, explosive energy reduces highwall stability and promotes the potential for rockfall, which are the fatal factors endangering operation safety. Therefore, it is necessary to carry out presplit blasting before casting for enhancing stripping bench safety and bench highwall control. On the other hand, presplit blasting has the roles of water draining, decreasing impact on the fixed slope, limiting rock blasting boundary, and improving highwall safety. Presplit 


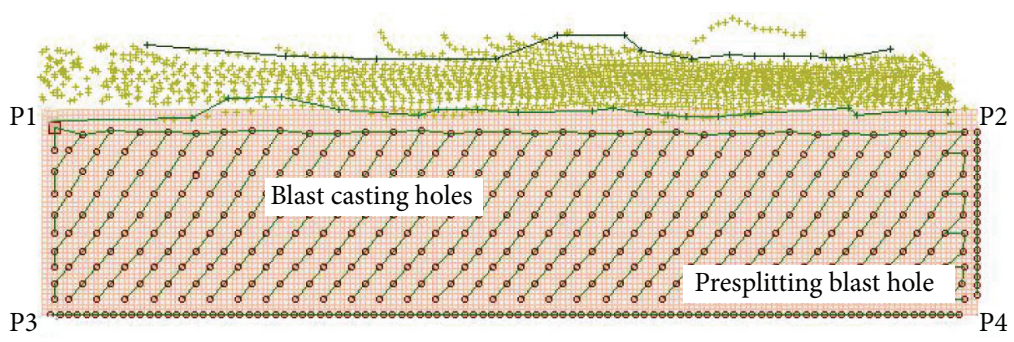

FIGURE 9: Design of blast casting.

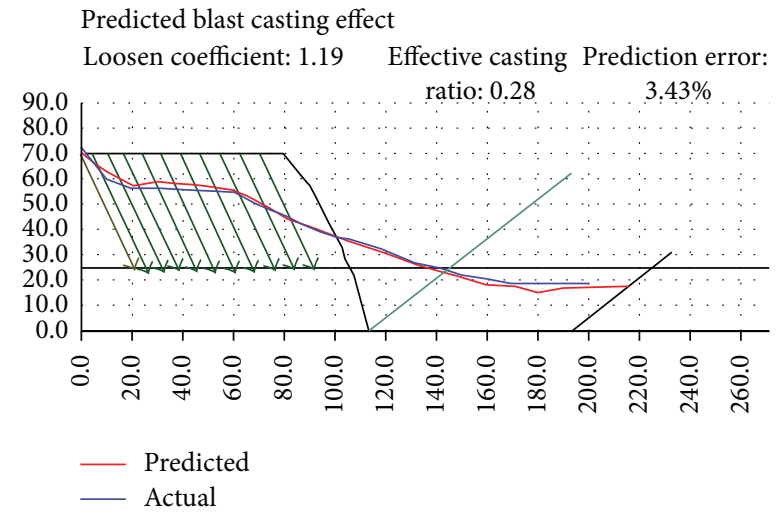

FIGURE 10: Schematic diagram of predicted blast casting effect.

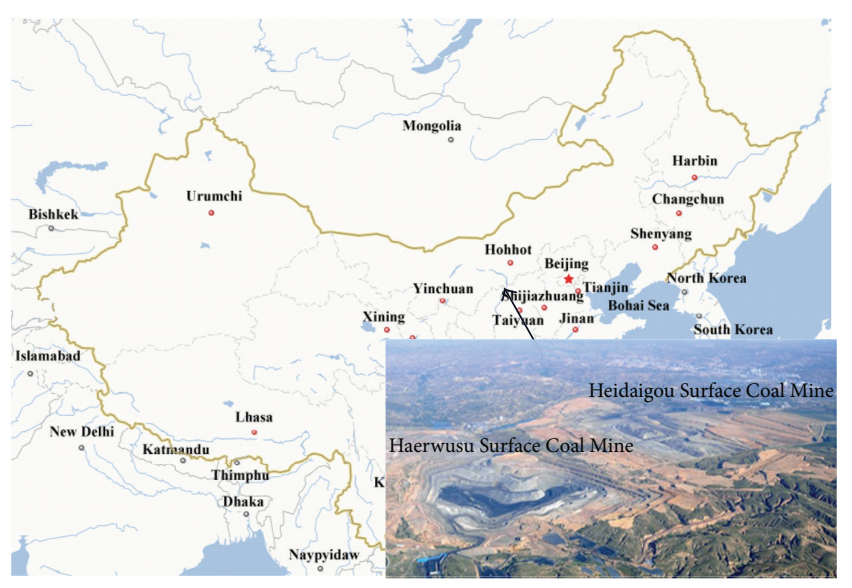

FIgUre 11: Heidaigou Surface Coal Mine location.

blasting used in surface coal mines is different from that of other open-pit mines. The best presplit results will be achieved from the surface coal mines with horizontal coal seams or having remarkable weakness plane in the contact position of coal and rock, as long as explosive charge is concentrated at the bottom of hole [24].

The spacing for presplit blasting can be expressed as

$$
S=\frac{D(P+T)}{T}
$$

where $S$ is hole space, $\mathrm{m} ; D$ is hole diameter, $\mathrm{m} ; P$ is of detonation wave pressure exerted on the walls of the hole, $\mathrm{MPa}$; $\mathrm{T}$ is rock tensile strength, $\mathrm{MPa}$.

According to actual condition of HSCM, presplit blasting can obtain better effect with hole space of $3.5 \mathrm{~m}$ and EUC of $0.77 \mathrm{~kg} / \mathrm{m}^{3}$. The presplit blasting effect of HSCM is shown in Figure 14.

Two monitoring points were arranged for observing blast vibration velocity, $\mathrm{S1}$, at the side of blast area without presplit blasting condition and $\mathrm{B} 1$ at the back of blast area with presplit blasting. The horizontal distance of monitoring points to explosion center was $800 \mathrm{~m}$, total explosive load was $960 \mathrm{t}$, and single-hole charge was $2 \mathrm{t}$. Blasting vibration velocities from monitoring points are shown in Table 3.

Based on the blast casting vibration monitoring with presplitting or not, the vibration velocities of the monitoring points are $14.5 \mathrm{~mm} / \mathrm{s}$ without presplitting and $10 \mathrm{~mm} / \mathrm{s}$ with presplitting. Finally, the decreasing amplitude ratio was determined as $31 \%$ according to formula (10). It proved that presplitting can reduce vibration effect of blast casting on rock slope by $1 / 3$.

3.3. Dragline Stripping Procedure. The first step in implementing blast casting is to establish a stripping bench, where holes are drilled, loaded, and fired, and the overburden casted by explosives energy into the mined-out pit at a certain length of working face, which was divided into four sections, for drilling and charging, blasting and muck pile leveling, rehandling overburden by dragline, and coal excavating separately and alternately [25]. After the production bench is cleared of waste rock overburden, it is mined over its full length. This creates a mined-out pit serving as an inner dump for stacking casted overburden for the next mining width. The effective casting quantity of loose material below the angle of repose cannot be rehandled and the muck-pile within the original bench is leveled by bulldozer to obtain the desired contour while the dragline standing on the bench continued working on the rest of the materials.

The BE8750-65 dragline with bucket capabilities of $90 \mathrm{~m}^{3}$, boom length of $100 \mathrm{~m}$, rated suspended load of $289.4 \mathrm{t}$, and annual production capacity of $26.11 \mathrm{Mm}^{3}$ was adopted in HSCM since 2007. Working face was divided into two sections, one for stripping and another for coal excavating with each length of $1100 \mathrm{~m}$. A ramp ditch was set within the middle pit for transporting coal to semifixed crusher arranged along the end-wall ground as shows in Figure 15. 


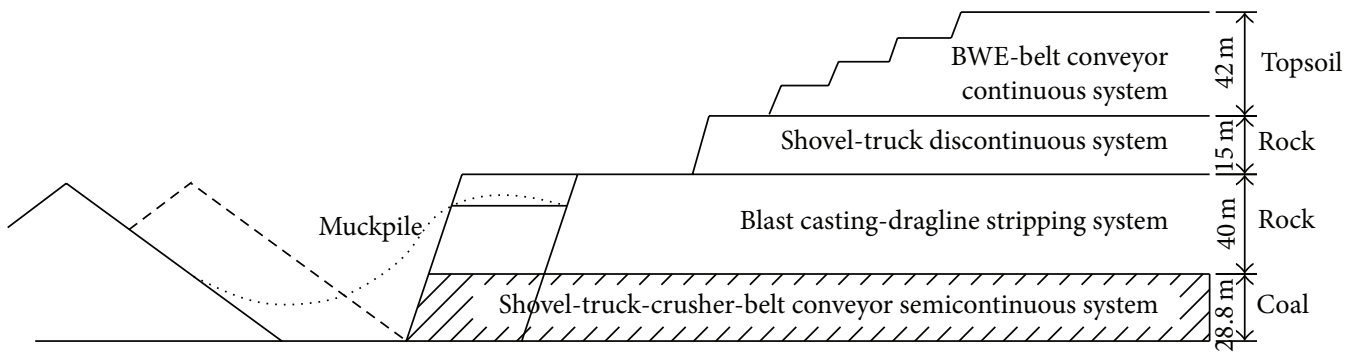

FIgURE 12: Mining technology systems of HSCM.

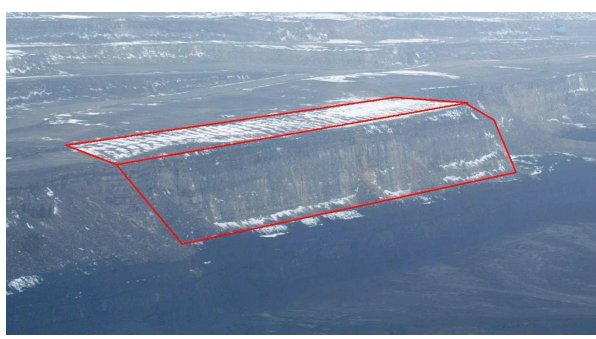

(a) Before blast

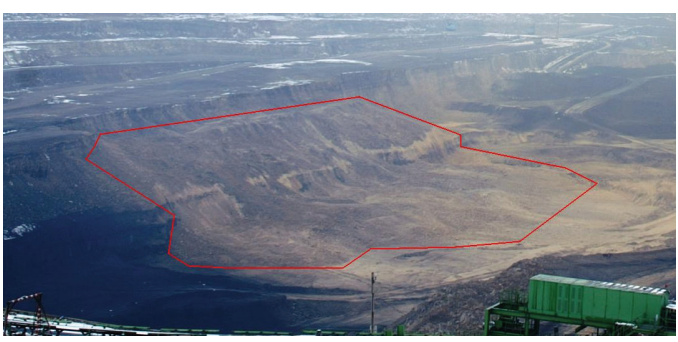

(b) After blast

FIGURE 13: Blast casting technique applied in HSCM.

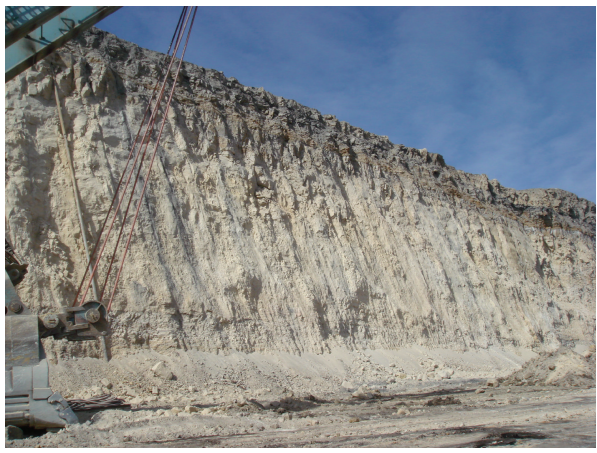

(a)

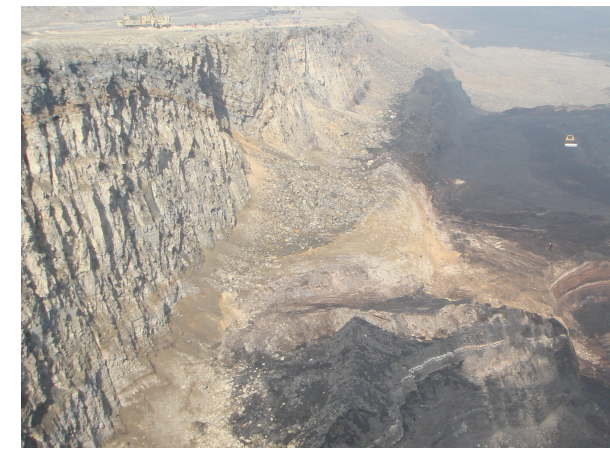

(b)

FIgURE 14: Presplit blasting effect of HSCM.

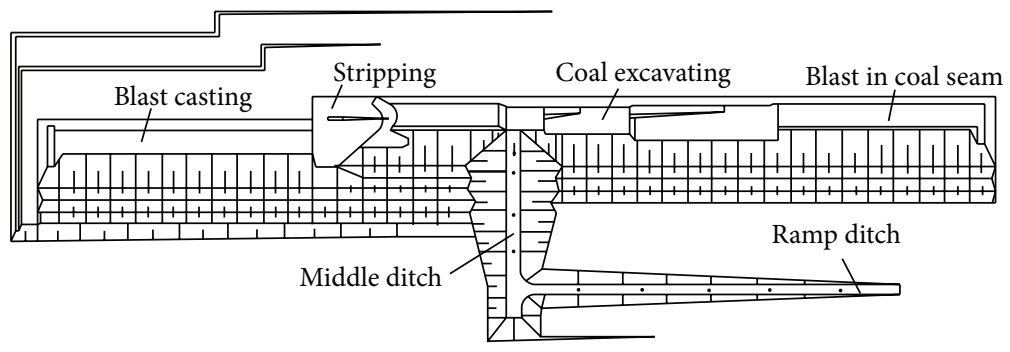

FIGURE 15: Operating process and coal excavating of dragline stripping.

TABLE 3: Blasting vibration velocity of monitoring points.

\begin{tabular}{lccccc}
\hline $\begin{array}{l}\text { Monitoring } \\
\text { points }\end{array}$ & Horizontal $(\mathrm{mm} / \mathrm{s})$ & Vertical $(\mathrm{mm} / \mathrm{s})$ & Axial $(\mathrm{mm} / \mathrm{s})$ & Vector resultant velocity $(\mathrm{mm} / \mathrm{s})$ & Horizontal distance $(\mathrm{m})$ \\
\hline B1 & 8.51 & 4.3 & 9.9 & 10 & 800 \\
B1 & 12.6 & 5.59 & 12.4 & 14.5 & 800 \\
\hline
\end{tabular}


When the dragline is working in the left district for stripping overburden, coal is excavated by shovel in the right district, and trucks transport coal from working face to semifixed crusher via the middle ramp ditch. With development of mining and stripping engineering, coal is exposed after finishing stripping operation on the left mining district and coal is excavated in right one as well, shovels move to left district for coal mining operation and blast casting in right one. Meanwhile, dragline moves into right district for stripping material from end-wall and middle ramp ditch. So the next cycle of operations is the right district for overburden stripping and left one for coal excavating.

3.4. Optimum Shift Distance of Middle Ditch. According to the features of the middle ditch in the inner dump, it can be decomposed into three parts of the horizontal transport section $C$, lengthways upgrade section $B$, and transverse upgrade section A, as shown in Figure 16.

Section A. This section has no effect on the inner-dumping distance of the upper stripping bench, but it will increase to twice the stripping quantities when it is required to shift:

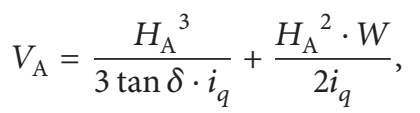

where $V_{\mathrm{A}}$ is the twice stripping quantities due to shift of middle ditch, $\mathrm{m}^{3} ; H_{\mathrm{A}}$ is upgrade height in section $\mathrm{A}, \mathrm{m} ; W$ is ramp width, $\mathrm{m} ; \delta$ is the loose material dumping angle, ${ }^{\circ} ; i_{q}$ is climb gradient of truck, $\%$.

Section B. This section is formed by stripping material backfill. The arrangement of the middle ditch has an impact on the inner dumping of the upper stripping bench, with the degree of influence given as

$$
Q_{\mathrm{B}}=\frac{H_{D} \cdot H_{\mathrm{B}}{ }^{2}}{4000 i_{q}{ }^{2}} \cdot\left(L_{D}+\frac{H_{D}}{\tan \beta}\right),
$$

where $Q_{B}$ is the degree of influence of section $B$ impact on the inner dumping of the upper stripping bench, $\mathrm{m}^{3} \cdot \mathrm{km} ; H_{\mathrm{B}}$ is upgrade height in section $\mathrm{B}, \mathrm{m} ; H_{D}$ is the influenced stripping bench height by section $\mathrm{B}, \mathrm{m} ; L_{D}$ is working face length above dragline stripping bench, $\mathrm{m} ; \beta$ is end-wall slope angle, .
Section C. The degree of influence of section C impact on the inner dumping of the upper stripping bench is

$$
Q_{C}=\frac{H_{D} \cdot L_{C}^{2}}{4000}\left(L_{D}+\frac{H_{D}}{\tan \beta}\right) \text {, }
$$

where $Q_{C}$ is the degree influence of section $B$ impact on the inner dumping of the upper stripping bench, $\mathrm{m}^{3} \cdot \mathrm{km} ; V_{\mathrm{C}}$ is the influenced inner-dumping volume of section $\mathrm{C}, \mathrm{m}^{3} ; L_{\mathrm{C}}$ is length of section $\mathrm{C}, \mathrm{m} ; H_{\mathrm{D}}$ is the influenced stripping bench height of section $\mathrm{C}, \mathrm{m}$.

With the advancing of mining and dumping, the length of section $\mathrm{C}$ and the haulage distance increase gradually with inner dumping. Meanwhile, the maximum length of section C $L_{\text {Cmax }}$ should be considered as the shift distance for the middle ditch. By taking total cost of material freight and middle ditch shift cost as target, an unconstrained-nonlinear model was established as

$$
\begin{aligned}
\min c= & \frac{c_{1} V_{\mathrm{A}}+c_{2} Q_{\mathrm{C}}}{L_{\mathrm{m}} h_{\mathrm{m}} L_{\mathrm{C} \max } \gamma} \\
= & \frac{c_{1} V_{\mathrm{A}}}{L_{\mathrm{m}} h_{\mathrm{m}} L_{\mathrm{C} \max } \gamma} \\
& +\frac{c_{2} H_{D}\left(L_{D}+H_{D} / \tan \beta\right) L_{\mathrm{Cmax}}}{4000 L_{\mathrm{m}} h_{\mathrm{m}} \gamma},
\end{aligned}
$$

where $c$ is unit cost, $¥ / \mathrm{t}$; $c_{2}$ is marginal transportation cost for inner dumping, $¥ / \mathrm{m}^{3} \cdot \mathrm{km} ; c_{1}$ is the twice stripping cost of ditch shifting, $¥ / \mathrm{m}^{3} ; L_{\mathrm{m}}$ is working face length of coal seams, $\mathrm{m} ; h_{\mathrm{m}}$ is average thickness of coal seams, $\mathrm{m} ; L_{\mathrm{Cmax}}$ is the shift distance of middle ditch, $\mathrm{m} ; \gamma$ is coal density, $\mathrm{t} / \mathrm{m}^{3}$.

The independent variables are continuous variables and derivable, and extreme value can be achieved by the method of derivation:

$$
\begin{aligned}
\frac{d c}{d L_{\mathrm{C} \max }}= & -\frac{c_{1} V_{\mathrm{A}}}{L_{\mathrm{m}} h_{\mathrm{m}} \gamma_{\mathrm{m}}} L_{\mathrm{Cmax}}{ }^{-2} \\
& +\frac{c_{2} H_{D}\left(L_{D}+H_{D} / \tan \beta\right)}{4000 L_{\mathrm{m}} h_{\mathrm{m}} \gamma_{\mathrm{m}}} .
\end{aligned}
$$

Assuming $d c / d L_{\mathrm{Cmax}}=0$, then

$$
\begin{aligned}
L_{\mathrm{Cmax}} & =\frac{2 \cdot c_{1} \cdot\left(H_{\mathrm{A}}{ }^{3} /\left(3 \cdot \tan \delta \cdot i_{q}\right)+\left(H_{\mathrm{A}}{ }^{2} \cdot W\right) /\left(2 \cdot i_{q}\right)\right)}{\sqrt{\left(c_{1}\left(H_{\mathrm{A}}{ }^{3} /\left(3 \cdot \tan \delta \cdot i_{q}\right)+\left(H_{\mathrm{A}}{ }^{2} \cdot W\right) /\left(2 \cdot i_{q}\right)\right) \cdot c_{2} \cdot H_{D} \cdot\left(L_{D}+H_{D} / \tan \beta\right)\right) / 1000}} \\
& =\frac{20 \sqrt{10} \cdot H_{\mathrm{A}} \cdot \sqrt{H_{\mathrm{A}} /(3 \cdot \tan \delta)+W / 2}}{\sqrt{\left(c_{2} / c_{1}\right) \cdot i_{q} \cdot H_{D} \cdot\left(L_{D}+H_{D} / \tan \beta\right)}} .
\end{aligned}
$$

With the major calculation parameters determined, the upgrade height in upgrade section $\mathrm{A}$ is $60 \mathrm{~m}$, the influenced stripping bench height of section $\mathrm{C}$ is $130 \mathrm{~m}$, end-wall slope angle above casting bench is $32^{\circ}$, ramp width is $40 \mathrm{~m}$, and the twice stripping cost is $10 ¥ / \mathrm{m}^{3}$. The optimum shift distance of the middle ditch is determined as $480 \mathrm{~m}$ according to formula 


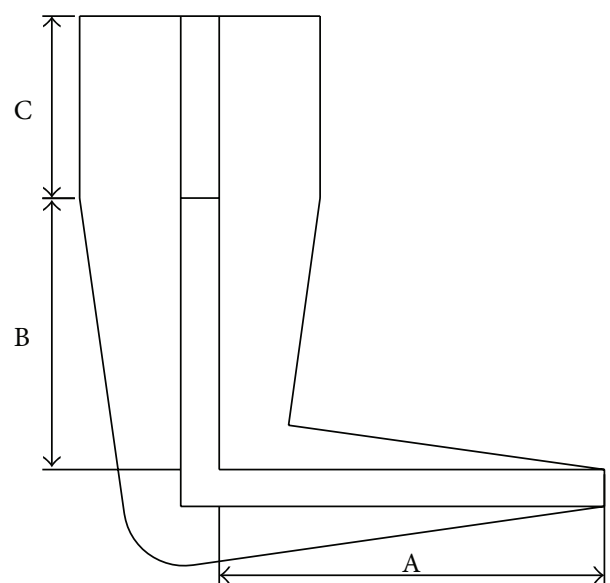

FIGURE 16: Basic shape of the transportation system with ramp.

(16); the middle ditch should be shifted after 6 blast casting mining panels being stripped.

\section{Conclusions}

(1) The three row blast holes close to the free face act as the main role on casting, ECR will decrease with increasing mining panel width, and it has a significant effect of increasing bench height to enhance explosion pressure. Moreover, there is a linear relationship among casting amount with bench height $H$ and mining panel width $W$. The effective amount casted into mined-out area will increase with the increasing height to width ratio $(H / W)$, while ECR has a positive correlation with bench height with a fixed mining panel width. Casting distance has a quadratic parabolic relationship with inclined angle of blast holes. Inclined holes can reduce resistance line, increase effective utilization ratio of explosive energy, make the bench slope more stable, and enhance working safety. ECR will increase with ECA and EUC increasing, respectively, but the increasing range decreases when ECA and EUC reach a certain value. Rock blackness decreases with the two adjacent holes in a row detonating at the same time, and the rock block will obtain higher initial velocity. Presplitting has the main effects on defining blast casting boundary, decreasing the blasting vibration and effects on the fixed slope, and enhancing water drainage. Blast hole pattern parameters acts as a key role in blast casting effect, on both smaller and oversized row, and hole distance will result in poor casting and breaking effect.

(2) Several mining systems were adopted in HSCM, the blast casting technique was applied at the rock bench above 6 th coal roof, and more than $34 \%$ of material was casted into inner dump with about $1 / 3$ stripping cost saved. By considering working processes and effect of blast casting and dragline, the basic bench parameters were determined as $80 \mathrm{~m}$ of mining panel width, $40 \mathrm{~m}$ of stripping bench height, and 75 degree of slope angle while the parameters for best blasting effect were determined as $9 \mathrm{~m}$ to $13 \mathrm{~m}$ of spacing and $7 \mathrm{~m}$ to $9 \mathrm{~m}$ of burden. Hole-by-hole initiation technique and milliseconds blasting were adopted to reduce the effects to both the highwall and the buildings.

(3) By adopting blast casting technique, the working face was divided into four sections with a ramp ditch set within middle pit for coal transporting. After overburden material was casted into minedout area, the muck pile was leveled by bulldozer and stripped by dragline. Overburden stripping and coal excavating were implemented separately and alternately in the two sections around the middle ramp ditch. According to the constructor of the middle ditch, it can be subdivided into three sections, and the relationships of each section's impact on overburden stripping volume to the haulage distance of the upper stripping bench were considered for establishing an unconstrained-nonlinear model. The optimization formula was thus deduced. The optimum shift distance of HSCM is $480 \mathrm{~m}$, and the middle ditch should be shifted after 6 blast casting mining panels being stripped.

\section{Conflict of Interests}

The authors declare that there is no conflict of interests regarding the publication of this paper.

\section{Acknowledgments}

This study was supported by the National Natural Science Foundation of China (51034005), the Fundamental Research Funds for the Central Universities (2010QNB23, 2011QNB25), and the Priority Academic Program Development of Jiangsu Higher Education Institutions.

\section{References}

[1] R. K. Singhal, H. G. Naidu, and S. P. Singh, "Influence of blasting techniques on open pit economics," Mining Engineering, vol. 41, no. 2, pp. 95-98, 1989.

[2] A. K. Mishra, M. Sinha, and M. Rout, "Cast blasting for improved mine economics," in Blasting in Mining-New Trends: 10th International Symposium on Rock Fragmentation by Blasting, FRAGBLAST 10, pp. 73-80, CRC Press, New York, NY, USA, 2013.

[3] R. R. Rollins and R. W. Givens, "Blast casting at an eastern strip mine," Transactions of the Metallurgical Society of AIME, no. 288, pp. 1871-1876, 1987.

[4] P. D. Dupree, "Applied drilling and blasting techniques for blast casting at trapper mine-potential to save on overburden removal," Mining Enigneering, vol. 39, no. 1, pp. 13-15, 1987.

[5] S. A. Tagieddin, "Applicability of blast casting technique in stripmining phosphate rock," Engineering Geology, vol. 33, no. 2, pp. 127-139, 1992. 
[6] P. D. Sharma, "Overburden side casting by blasting-an effective way of reducing operating cost in large opencast coal mines," Journal of Mines, Metals and Fuels, vol. 52, no. 11, pp. 284-288, 2006.

[7] S. K. Ray, A. Zutshi, and M. Sarkar, "Cast blasting-state of the art," Fragblast, vol. 3, no. 4, pp. 291-302, 1999.

[8] Y.-D. Zhang, H.-X. Fu, Q.-R. Wang, and S.-L. Xia, "Casting blast and analysis of mining parameters of stripping benchtechnical paper series for open cast method in surface mines (IV)," Journal of China University of Mining and Technology, vol. 32, no. 1, pp. 27-30, 2003.

[9] J. M. Tracy, "Increased production through cast blasting in surface coal mines," Journal of Explosives Engineering, vol. 3, no. 3, pp. 16-20, 22-23, 1985.

[10] D. P. Singh, M. M. Singh, and A. Katkar, "Blast casting in surface excavations-a global scenario," Mining Technology, vol. 78, no. 894, pp. 55-59, 1996.

[11] G. K. Pradhan, O. M. Prakash, and N. R. Thote, "Blast free mining in Indian surface coal mines-current trend," in Mine Planning and Equipment Selection, pp. 335-357, Springer, 2014.

[12] X.-L. Li, D.-S. Liu, L.-H. He, L.-F. Luan, and Z.-Y. Zhang, "Influences of bench height of an open-pit coal mine on cast percentage," Explosion and Shock Waves, vol. 32, no. 2, pp. 211$215,2012$.

[13] A. P. Grippo, "How to get more cast per blast," Coal Age, vol. 89, no. 12, pp. 63-69, 1984.

[14] M. Uttarwar and R. Yerpude, "Overburden cast blasting with angled drilling - an evaluation for improving productivity of indian surface coal mines," Journal of Mines, Metals and Fuels, vol. 58, no. 6, pp. 147-167, 2010.

[15] N. P. Chironis, "Angled drilling aids casting," Coal Age, vol. 89, no. 1, pp. 64-67, 1984.

[16] B. P. Li, C. Liu, S. L. Wang, and J. Ma, "Experimental study on cast blasting in loose medium," Blasting, vol. 27, no. 1, pp. 11-13, 2010.

[17] X.-L. Li, "Effect of casting parameters on the cast percentage of high bench cast blasting," Transaction of Beijing Institute of Technology, vol. 31, no. 11, pp. 1265-1269, 2011.

[18] P. L. Wang, W. Zhou, H. C. Yang, and G. Y. Zhang, "Analysis on suitable row distance of casting blast in surface coal mine," Coal Engineering, no. 11, pp. 72-74, 2011.

[19] H.-X. Fu and K.-M. Li, "Analysis of high bench cast blasting parameters in surface coal mines," Journal of the China Coal Society, vol. 31, no. 4, pp. 442-445, 2006.

[20] X.-L. Li, L.-H. He, L.-F. Luan, and Z.-Y. Zhang, "Simulation model for muckpile shape of high bench cast blasting in surface coal mine," Journal of the China Coal Society, vol. 36, no. 9, pp. 1457-1462, 2011.

[21] X.-H. Ding, K.-M. Li, W.-M. Hu, and Z.-Y. Ren, "Prediction of optimum muck pile casting shape during blasting: a nonlinear theory," Journal of China University of Mining \& Technology, vol. 41, no. 5, pp. 764-769, 2012.

[22] M. L. Bricker and J. R. Key, "Dragline stripping methods enhanced by explosives casting at Bridger coal mine," Mining Engineering, vol. 43, no. 4, pp. 392-394, 1991.

[23] M. S. Sandhu and G. K. Pradhan, "Improvements in blastingan Indian case study of surface coal mines," in Proceedings of the International Conference on Reliability, Production, and Control in Coal Mines, pp. 136-142, September 1991.

[24] N. P. Chironis, "Improving blasting improves efficiency," Coal Age, vol. 26, no. 7, pp. 36-41, 1989.
[25] T. Shang, Y.-D. Zhang, K.-M. Li, and A.-M. Tian, "Optimal selection of coal haulage system in open cast mining-technical paper series for open cast method in surface mines (III)," Journal of China University of Mining \& Technology, vol. 31, no. 6, pp. 571-574, 2002. 


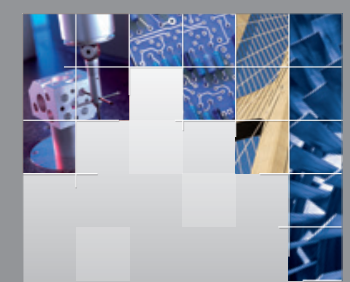

\section{Enfincering}
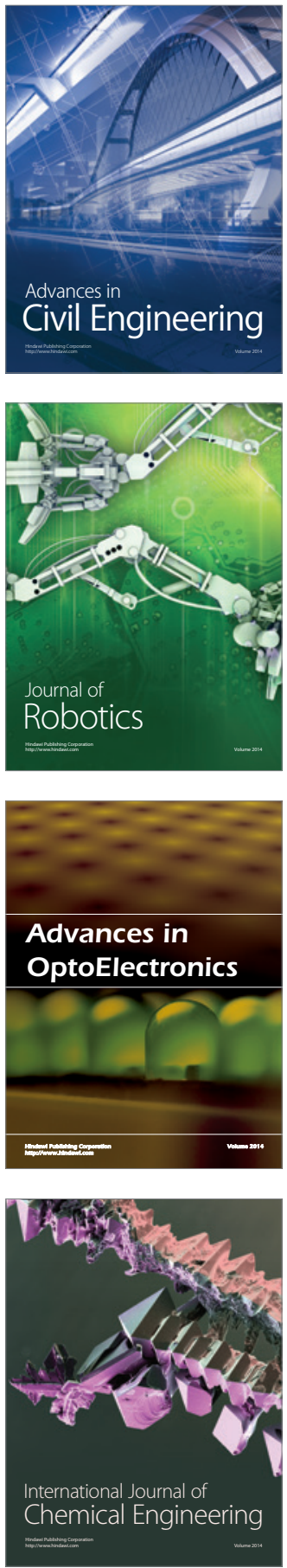

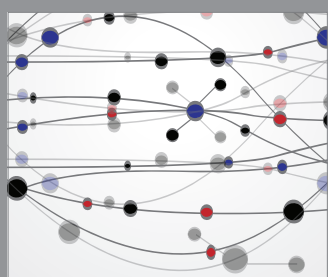

The Scientific World Journal

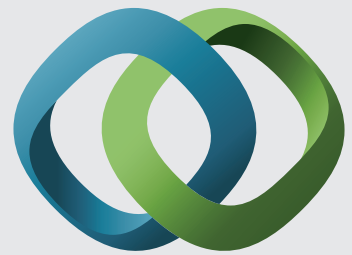

\section{Hindawi}

Submit your manuscripts at

http://www.hindawi.com
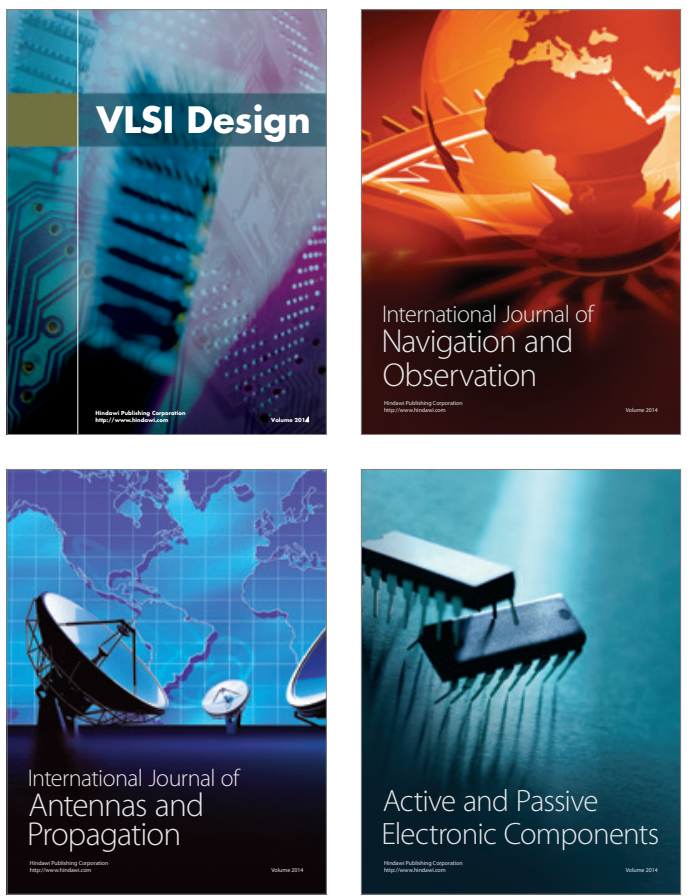
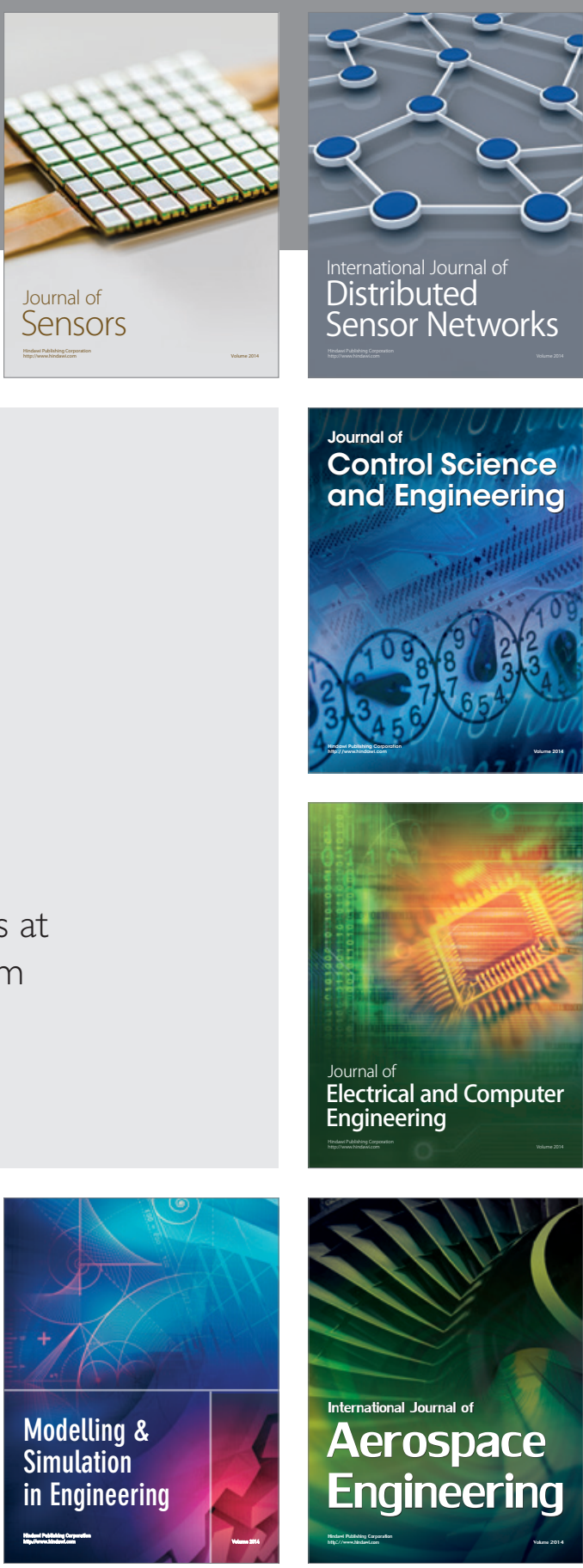

International Journal of

Distributed

Sensor Networks

Journal of

Control Science

and Engineering
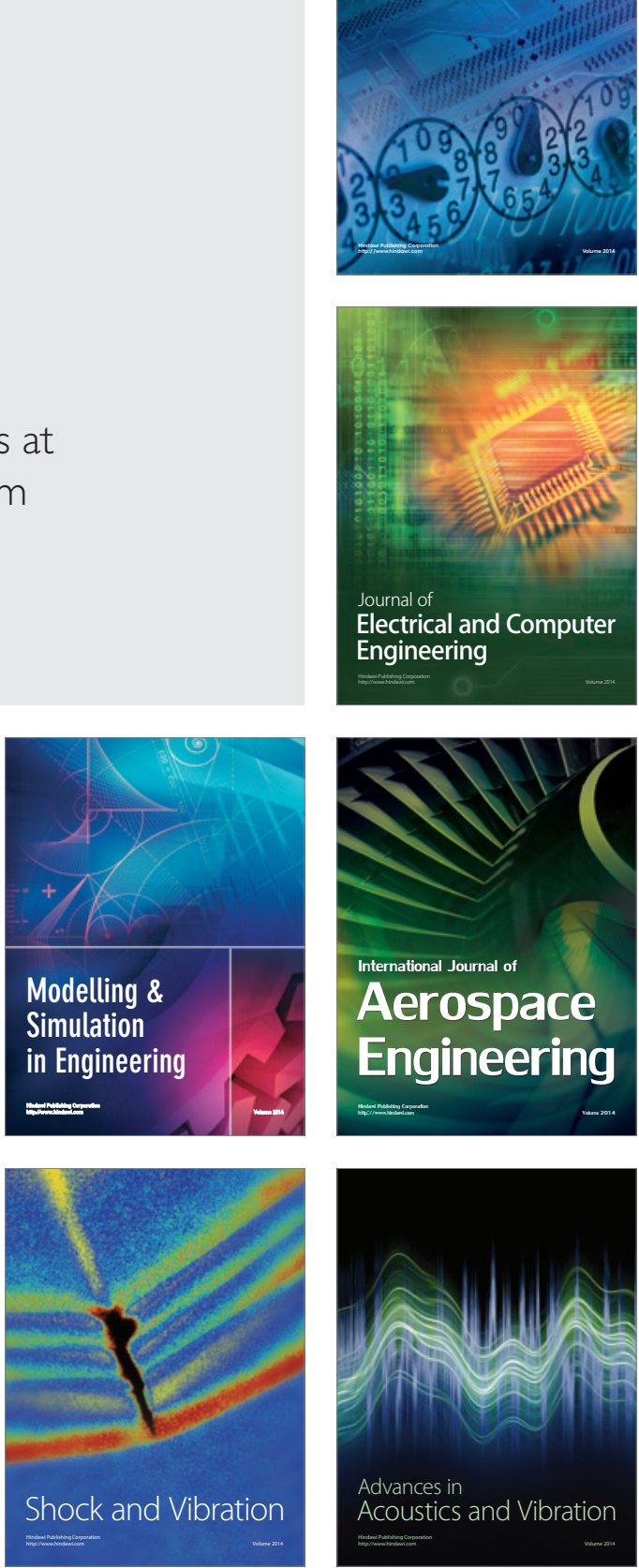